design flaw in the omission of any 'no preference' check box in the questionnaire.

Unfortunately ethnic minorities were under-represented in this survey and such groups may have important differences in preference for treatment device. It is difficult to correlate patient preference with greater levels of compliance within the confines of a self-administered questionnaire. These issues could be explored further by way of a prospective double blind placebo controlled randomised study comparing compliance with either inhaler or tablet.

\section{CONCLUSION}

These findings emphasise the varying preferences exhibited by patients. In a disease such as asthma where compliance is a major issue, it is important to take into account patients' own preference for device and route of delivery. ${ }^{3}$ The majority of patients, particularly the young and those on more than three inhalers would prefer additional therapy via the oral route. Such preferences should be identified when prescribing in asthma.

\section{ACKNOWLEDGEMENT}

The authors wish to thank Merck, Sharp and Dohme for financial support of this study.

\section{REFERENCES}

1. The British Guidelines on Asthma Management:1995 Review and Position Statement. Thorax 1997;52(1): S1-21.

2. Fabbri LM, Piatella M, Caramori G, Ciaccia.A. Oral vs. Inhaled Asthma Therapy. Drugs 1996; 52[Suppl 6]: 20-8.

3. Kelloway JS, Wyatt RA, Adlis SA. Comparison of patients' compliance with prescribed oral and inhaled asthma medications. Archives of Internal Medicine 1994;154:1349-52.

4. Selby C, Engleman HM, Fitzpatrick MF, Sime PM, Mackay TW, Douglas NJ. Inhaled salmeterol or oral theophylline in nocturnal asthma? Am J Respir Crit Care Med 1997; 155:104-8.

5. Tettersell MJ. Asthma patients' knowledge in relation to compliance with drug therapy. Journal of Advanced Nursing 1992:18: $103-13$

6. Osman L. The patient perspective. What should a new anti-asthma agent provide? Drugs 1996;52[Suppl 6]: 29-35.

7. Weinberg EG, Naya I. Treatment preferences of adolescent patients with asthma. Pediatric allergy and immunology 2000;11[1]:49-55.

8. Huse DM, Klaus DH, Piercev GE. Compliance with inhaled versus oral asthma medications. American Journal of Respiratory and Critical Care Medicine 1997; 155: A568.

9. Alessandro F, Vincenzo ZG, Marco S. Compliance with pharmacologic prophylaxis and therapy in bronchial asthma. Ann Allergy 1994; 73:135-40.

10. Chapman KR, Walker L, Cluley S, Fabbri L. Topical Reviews: Improving patient compliance with asthma therapy. Resp Med 2000; 94:2-9.

11. Malo JL, Cartier A, Ghezzo H. Comparison of four-times-a-day and twice-a-day dosing regimens in subjects requiring 1200ug $\mathrm{r}$ less of budesonide to control mild to moderate asthma. Resp Med 1955:89:537-43

\title{
Home or surgery based screening for chronic obstructive pulmonary disease (COPD)?
}

\author{
D A Seamark, S Williams, S Timon, A Ward, D Ward, C Seamark, M Pinnuck, R Powell, D Halpin
}

\author{
ABSTRACT \\ Aims \\ To compare the effectiveness of opportunistic spirometric screening \\ of patients attending a general practice surgery with screening on \\ randomly selected home visits. \\ Method \\ 100 patients aged $45+$ attending the Honiton Surgery (surgery \\ group) and 100 randomly selected patients visited at their homes \\ (home group) were invited to perform spirometry and complete a \\ symptom and medication questionnaire. Main outcome measures \\ were successful completion of spirometry and questionnaire and an \\ estimate of COPD prevalence. \\ Results \\ Surgery assessments were successful in $94 / 100$ (95\% C.I. $89 \%$ to \\ $99 \%$ ) cases. Eighteen percent of those visited at home refused the \\ invitation to attend for spirometry; $33 \%$ (95\% C.I. $24 \%$ to $42 \%)$ \\ resulted in a successful assessment; there was no. reply when visit- \\ ing $46 \%$ of cases and $3 \%$ of he visits were refused or terminated \\ on the day. \\ The mean age of the surgery group and home group was 63.7 years \\ and 64.5 years respectively. The mean time per patient was 17 \\ minutes in the surgery group and 1 hour 26 minutes in the home
}

group.

Twenty five $(27 \%, 95 \%$ C.I. $18 \%$ to $36 \%)$ of those assessed in the surgery group and $10(30 \%, 95 \%$ C.I. $14 \%$ to $46 \%)$ of the home group had an $\mathrm{FEV}_{1}<80 \%$ predicted. Of these, $14 / 25(56 \%)$ and $4 / 10(40 \%)$ were current or ex-smokers. Of these, eight and three respectively had cough, wheeze or breathlessness, giving an overall COPD prevalence of $11 / 127$ (9\%, 95\% C.I. $0 \%$ to $19 \%)$. Three of these eleven (27\%) had mild disease, $7 / 11$ (64\%) moderate and 1/11 (9\%) severe. The mean age of the patients with COPD was 70.8 years. Four of the eleven $(36 \%)$ patients with COPD already had a diagnosis recorded in their records (3 COPD, 1 asthma). Analysis of surgery attendance (any health care professional) of all patients aged 45 and above, indicated that over a one year period $79.1 \%$ (95\% C.I. $78.2 \%$ to $80.0 \%$ ) and over a two year period $89 \%(95 \%$ c.i. $88.3 \%$ to $89.7 \%$ ) of the total practice population attended on at least one occasion.

\section{Conclusion}

Opportunistic spirometric assessment of patients routinely attending surgery results in a high uptake; over a period of two years around $84 \%$ of the target population could be assessed. Home visiting may be used for reaching those not routinely attending the surgery. 


\section{BACKGROUND}

Management of chronic disease accounts for an increasingly large proportion of NHS workload. Chronic obstructive pulmonary disease (COPD) accounts for over 25,000 deaths in England and Wales each year: approximately $6.5 \%$ of all male deaths and $4 \%$ of all female deaths. ${ }^{2,3}$ The burden of disease is however considerably greater. Morbidity from COPD is high and patients are frequent users of primary and secondary care facilities. As many as 1 in 8 hospital admissions may be due to $\mathrm{COPD}^{4}$ and consultation rates in General Practice are 2-4 times higher than those for angina. ${ }^{5}$ Primary care interest in-patients with COPD has increased recently, partly as a result of the desire to differentiate patients with COPD from those with asthma and partly as a result of the publication of guidelines on COPD management. ${ }^{2}$

Unlike asthma, true estimates of the prevalence of COPD depend on determination of airflow limitation using spirometry, rather than being amenable to questionnaire surveys. Consequently there is little data on the true prevalence of COPD or the morbidity associated with this. We are unaware of any data comparing the information held in a General Practice computerised database with the actual prevalence or level of symptoms.

Studies have shown an increase in the number of cases of obstructive airways disease (asthma and chronic obstructive pulmonary disease) in all age groups over the past few decades. ${ }^{6,7}$ Prevalence studies have indicated substantial numbers of undiagnosed COPD cases particularly amongst the elderly. ${ }^{8,910}$ However, a recent study screening older patients (aged 60-75) for obstructive airways disease in a British general practice indicated that few new cases were found and of those none had severe disease. ${ }^{11}$ An editorial accompanying the latter study indicated that there is still uncertainty as to true prevalence of COPD and that attention should be focussed as to the benefits of screening younger age groups to detect disease and institute measures to prevent deterioration in later life. $^{12}$

This pilot study was devised in order to determine the most effective way in which to screen an entire general practice population for obstructive airways disease. The screening process also provided an opportunity to examine the electronic medical records for morbidity data and medication prescribed for each subject.

\section{METHOD}

The setting was the Honiton Group Practice, a research practice receiving National Health Service (NHS) Resarch and Development support funding. The practice area is semi-rural with a population of approximately 15,000 patients. Honiton is a small market town in East Devon with an age, sex and social class distribution typical of many English towns. The practice holds extensive computerised clinical records and prescribing data on all patients registered. Asthma and COPD patients receive regular review by their own doctor and by two practice nurses trained in primary care respiratory medicine.
The pilot study compared the participation rates and time taken to complete assessment of 100 patients aged 45 and over attending the surgery with home visits to a randomly selected group of 100 patients aged 45 and older. Assessment consisted of performing satisfactory spirometry and completion of a symptom and medication questionnaire.

\section{Surgery Assessments}

The computerised appointments system was scrutinised the day before the surgery in question by a senior receptionist who highlighted suitable candidates within the relevant age group. Patients were selected at approximately half-hour intervals from each general practitioner surgery list in turn so as to allow the research nurse time to perform the spirometric assessment. On the day of attendance the relevant patient was identified when checking in at reception and asked if they were happy to participate in the study. If the patient consented they were handed an explanatory letter and the questionnaire to be completed while they were waiting for their appointment.

Using the appointments computer screen the research nurse was able to see when the patient had checked in and could call the patient in for spirometry either before (if time permitted) or after the appointment with the GP or other health professional. Where necessary the research nurse helped with completion of the questionnaire. The nurse explained the use of the spirometer (what it measures, the measurement technique and its importance) for the benefit of the patient. Patients' age was recorded and their height was measured.

Spirometry was performed according to standard procedures with the machine calculating results based on the best three attempts. The nurse recorded results onto the questionnaire and any other relevant information, such as recent chest infection and poor technique.

\section{Community visits}

The practice computer was used to generate a list of patients aged 45 years and older; and each patient numbered. One hundred patients were selected using random number tables. Explanatory letters on the project were sent to the patients at least two weeks before a proposed visit. Patients were given the opportunity to decline a visit by returning a reply-paid refusal form or by telephoning the surgery direct.

The research nurse prepared visits on a geographical basis where possible; these were performed on a variety of weekdays and at different times of the day ranging from $9 \mathrm{am}$ to $7 \mathrm{pm}$. Visits were commenced after the start of British Summer Time.

Calling slips were left for patients who were not in when the nurse called to assure them that no further action would be necessary.

\section{Database analysis}

The computerised surgery database was examined for diagnostic and prescription data for patients with significant airways obstruction and significant declared symptoms.

\section{A Seamark}

S Williams

S Timon

A Ward

D Ward

C Seamark

\section{Pinnuck}

The Honiton Group Practice, Marlpits Road, Honiton, EX14 8DD.

Dr Roy Powell, Lecturer in health services research.

Exeter \& North Devon Research \& Development Support Unit (RDSU), Postgraduate Medical School, Exeter, EX2 5EQ.

Dr David M. G. Halpin, Consultant Physician and Senior Lecturer in Respiratory Medicine.

Royal Devon \& Exeter Hospital, Barrack Road, Exeter, EX1 5DW

Correspondence to:

Dr David Seamark

The Honiton Group Practice, Marlpits Road, Honiton, EX14 8DD

David.Seamark@ gp-L83002.nhs.uk

\section{Acknowledgements}

The Honiton Group Practice is a research practice funded by the NHS

Executive South and West.

The project was funded by a start-up grant from the NHS Executive South and West Research and Development Directora

Date Submitted: 20:07:00

Date Accepted:26:05:01

Prim Care Respir J 2001: 10(2); 30-33 
Table 1. Respiratory questionnaire results

\begin{tabular}{|c|c|c|c|c|c|}
\hline & & \multicolumn{2}{|c|}{$\begin{array}{c}\text { Surgery } \\
(n=94)\end{array}$} & \multicolumn{2}{|c|}{$\begin{array}{l}\text { Home } \\
(n=33)\end{array}$} \\
\hline & & No. & $\%$ & No. & $\%$ \\
\hline \multicolumn{2}{|c|}{ Daily cough for $>3$ months each year } & 21 & 22.3 & 2 & 6.1 \\
\hline \multicolumn{2}{|c|}{ Daily phlegm for $>3$ months each year } & 16 & 17.0 & 3 & 9.1 \\
\hline \multirow[t]{3}{*}{ Breathlessness: } & Hurrying on hills & 15 & 16.0 & 3 & 9.1 \\
\hline & On level with peers & 9 & 9.6 & 3 & 9.1 \\
\hline & On level at own pace & 16 & 17.0 & 10 & 30.3 \\
\hline \multicolumn{2}{|c|}{ Wheezing or whistling in chest } & 30 & 31.9 & 4 & 12.1 \\
\hline \multicolumn{2}{|c|}{ Woken at night by breathlessness } & 12 & 12.8 & 6 & 18.2 \\
\hline \multicolumn{6}{|c|}{ Off work because of chest illness } \\
\hline \multicolumn{2}{|l|}{ with phlegm } & 16 & 17.0 & 7 & 21.2 \\
\hline \multirow[t]{3}{*}{ Ever told had: } & Asthma & 17 & 18.1 & 5 & 15.2 \\
\hline & Chronic bronchitis & 8 & 8.5 & 3 & 9.1 \\
\hline & Emphysema & 3 & 3.2 & 1 & 3.0 \\
\hline \multicolumn{6}{|c|}{ Taken any medication } \\
\hline \multicolumn{2}{|c|}{ for breathing in past year } & 28 & 29.8 & 11 & 33.3 \\
\hline \multicolumn{2}{|c|}{ Have a beta agonist inhaler } & 12 & 12.8 & 15 & 45.5 \\
\hline \multirow[t]{4}{*}{ Use it: } & $>4 x$ day & 1 & 8.4 & 1 & 6.7 \\
\hline & $3-4 x$ day & 4 & 33.3 & 4 & 26.7 \\
\hline & $1-2 x$ day & 4 & 33.3 & 5 & 33.3 \\
\hline & $<1 \times$ day & 3 & 25.0 & 5 & 33.3 \\
\hline \multicolumn{2}{|c|}{ Have an anticholinergic inhaler } & 5 & 5.3 & 2 & 6.1 \\
\hline \multirow[t]{4}{*}{ Use it: } & $>4 \times$ day & 1 & 20.0 & 1 & 50.0 \\
\hline & $3-4$ x day & 1 & 20.0 & & \\
\hline & $1-2 \times$ day & 1 & 20.0 & & \\
\hline & $<1 \times$ day & 1 & 20.0 & & \\
\hline \multicolumn{2}{|l|}{ Have a preventer } & 13 & 13.8 & 4 & 12.1 \\
\hline \multirow[t]{3}{*}{ Use it: } & Never & 3 & 23.0 & 2 & 40.0 \\
\hline & Only occasionally & 2 & 15.4 & 1 & 20.0 \\
\hline & Every day & 8 & 61.6 & 2 & 40.0 \\
\hline \multicolumn{2}{|c|}{ Ever use another person's inhalers } & 1 & 1.1 & 1 & 3.0 \\
\hline \multirow[t]{7}{*}{ Current smoking: } & Never & 80 & 85.1 & 20 & 60.6 \\
\hline & $<5 /$ day & 2 & 2.1 & 1 & 3.0 \\
\hline & 5-9/day & 5 & 5.3 & 2 & 6.1 \\
\hline & 10-20/day & 7 & 7.4 & 1 & 3.0 \\
\hline & $>20 /$ day & 0 & 0.0 & 0 & 0.0 \\
\hline & Ex-smoker & 30 & 31.9 & 9 & 27.3 \\
\hline & Current or ex-smoker & 44 & 46.8 & 13 & 39.4 \\
\hline \multicolumn{6}{|c|}{ In past year, because of difficulty breathing: } \\
\hline \multicolumn{2}{|c|}{ Attended a GP surgery } & 20 & 21.2 & & \\
\hline \multicolumn{2}{|c|}{ Called GP to house } & 8 & 8.5 & 8 & 24.2 \\
\hline \multicolumn{2}{|l|}{ Been to $A \& E$} & 8 & 8.5 & 5 & 15.2 \\
\hline Been admitted & & 8 & 8.5 & 6 & 18.2 \\
\hline Due to heart pro & lems & 7 & 7.4 & 4 & 12.1 \\
\hline Have low FEV 1 & $<80 \%$ predicted) & 25 & 26.6 & 10 & 30.3 \\
\hline
\end{tabular}

Analysis jobs were run to determine attendance at surgery for all patients to any health care professional over the period of one and two years.

\section{RESULTS}

The assessment of patients attending surgery for routine appointments occurred with minimal disruption of normal surgery activity. Of 100 invited to participate, two declined, giving a response rate of $98 \%$ and spirometry was not possible in four patients seen at the surgery because of inadequate technique, producing 94 complete data sets $(94 \%, 95 \%$ c.i. $89 \%$ to $99 \%)$. Of the 94 screened patients $49 \%$ were aged $45-64$ years and $51 \% 65$ years and older.

Home visits proved more problematic. Of 100 invitations, 18 replied declining to participate. Of the 82 attempted visits 33 (33\%, $95 \%$ C.I. $24 \%$ to $42 \%)$ resulted in a successful assessment with both spirometry and the questionnaire being completed. No reply when visiting occurred in 46 (46\%) cases 3 (3\%) visits were refused or terminated on the day. Of 53 patients aged 45-64, 13 (25\%) and of 47 patients aged 65 and over, $20(43 \%)$ were successfully screened at home. Of the 33 patients screened at home $39 \%$ were aged $45-64$ years and $61 \%$ were 65 years and over.

Surgery assessments were organised in clinics providing 16-minute appointments. With a success rate of $94 \%$ the average time for successful assessment was 17 minutes. The 33 successful home assessments took 47 hours 30 minutes of nurse time (taking into account the large number of patients not being at home at the time of visit) resulting in a successful home assessment requiring 1 hour 26 minutes of nurse time.

The mean ages of the surgery and home groups were 63.7 years and 64.5 years respectively (NS).

The results of the questionnaire survey and of spirometry for both surgery and home visit groups combined are shown in Table 1 . Twenty five $(27 \%, 95 \%$ c.i. $18 \%$ to $36 \%)$ of the surgery group and $10(30 \%, 95 \%$ c.i. $14 \%$ to $46 \%$ ) of the home visit group had an $\mathrm{FEV}^{1}$ $<80 \%$ predicted. Of these, $14 / 25(56 \%)$ and $4 / 10$ (40\%) respectively were ex-smokers. Of these 8 had coughs and 3 had wheeze or breathlessness, giving an overall prevalence of COPD of $11 / 127(9 \%, 95 \%$ c.i. $0 \%$ to $19 \%))^{2}$ Three of the eleven $(27 \%)$ of these had mild disease, $7 / 11$ (64\%) moderate and 1/11 (9\%) severe. All of these had a history of smoking.

The mean age of the 11 patients with COPD was 70.8 years and 3 had a diagnosis of COPD recorded in their medical records and one a diagnosis of asthma. These four $(36 \%)$ patients stated they were receiving inhaled bronchodilators and inhaled corticosteroids and these data were confirmed in the medical records.

A retrospective analysis of surgery attendances of all patients aged 45 years and above to any healthcare professional indicated that over a one year period $79.1 \%(95 \%$ c.i. $78.2 \%$ to $80 \%)$ and over a two year period $89 \%$ (95\% c.i. $88.33 \%$ to $89.7 \%$ ) of the total practice population attended on at least one occasion. This is likely to be an underestimate of the potential screening population as patients who had left the practice during the preceding two years were excluded from the analysis and patients often attend surgery for reasons other than a healthcare appointment.

\section{DISCUSSION}

Previous published studies of screening for chronic airways obstruction have produced variable response 
rates to the initial invitation to screening. Studies from Manchester, $\mathrm{UK}^{9}$ and the Netherlands ${ }^{13}$ produced rates of $62.5 \%$ and $66 \%$ respectively. Studies from single general practices in the $\mathrm{UK}^{11,12}$ of $81 \%$ and $93 \%$ respectively. All of the studies involved postal invitations and not opportunistic screening.

We have shown that opportunistic assessments of patients attending surgery results in high uptake of spirometry with a response rate of $94 \%$ obtained under normal working surgery conditions. High uptake depended upon having a well-trained and motivated nurse with adequate time for the assessment. The use of a computerised surgery appointments system allowed forward planning of the assessments and informed the nurse when the patient had been checked in. The retrospective analysis of surgery attendances indicated that with a response rate of $94 \%$ around $73 \%$ of patients aged 45 and over could be assessed over a period of one year and $84 \%$ over two years. With the close association of smoking cigarettes with a diagnosis of COPD we would propose targeting patients with a positive smoking history to improve the detection rate. It is possible that demonstration of impaired spirometry may prove a powerful incentive for smoking cessation. Over a period of one year around $73 \%$ of the target population and over a period of two years around $84 \%$ of the target could be assessed in the surgery.

In this study, home visiting wasa less efficient method of recruitment for routine screening. A low rate of assessment resulted mainly from patients not being at home. This is reflected in the lower percentage of patients successfully screened aged under 65 years who were likely to be at work. This could be largely overcome by making prearranged appointments, especially after working hours, which would probably raise response rate to around two thirds of those invited to participate. However, home visiting could be used for reaching those people not routinely attending the surgery, though at higher costs in terms of nursing time. We detected a prevalence of COPD of around $9 \%$, which is in agreement with other studies of prevalence. ${ }^{9,711}$ Only 3 of the 11 cases with a low FEV, ${ }^{1}$ who had been smokers and had symptoms, had a diagnosis of COPD recorded in the medical records indicating a high level of undetected significant disease. Current or ex-smokers accounted for $45 \%$ of the screened population with only $14 \%$ being current smokers. This is lower than the national average and probably reflects the older age distribution of the screened group.

The strengths of this study include confirmation of the relevant nature of the computerised appointments system employed in the surgery allowing accurate an easy identification of potential candidates for assessment. The practicality of performing assessment in surgery with minimal disruption to routine functioning has been demonstrated.
The study only set out to detect airways obstruction and not perform reversibility testing. This procedure would involve more nurse time, possible prescription of medication and the need for re-assessments; these were outside the scope of this pilot study.

This study has provided valuable data and experience for the planning of a full-scale COPD prevalence and smoking cessation study. The method of screening would primarily be opportunistic surgery based assessments of smokers over a period of two years. For those not attending surgery over this period, specific surgery invitations and home visiting would enhance coverage of the population. The implications of case detection and organised smoking cessation therapy would have large organisational and cost implications and would be subjected to health economic analysis.

\section{CONCLUSION}

Opportunistic spirometric assessment of patients routinely attending surgery results in a high uptake; over a period of two years around $84 \%$ of the target population could be assessed. Home visiting may be used for reaching those not routinely attending the surgery.

\section{REFERENCES}

1. Davis RH, Wagner EH, Groves T. Managing chronic disease. BMJ 1999;318:1090-1091.

2. BTS Guidelines for the management of chronic obstructive pulmonary disease. Thorax 1997:52 (Suppl 5):S1-S28.

3. Office of Population Censuses and Surveys. Mortality statistics, cause: England and Wales 1992. Series DH2 no. 19. London HMSO, 1993.

4. Pearson MG, Littler J, Davies PDO. An analysis of medical workload by speciality and diagnosis n Mersey: evidence of a specialist to patient mismatch. JR Coll Phys 1994;28:230-234

5. McCormick A, Fleming D, Charlton J. Morbidity statistics from general practice: Fourth national study 1991-2. London: Office of Population Censuses and Surveys, 1995.

6. Weiss KB. An overview of recent trends in asthma epidemiology. Eur Respir Rev 1996;35:101-4.

7. Tirimanna PRS, Van Schayck CP, Den Otter JJ, Van Herwaarden, CLA, Van Den Boom G, Van Grunsven PM, Van Den Bosch WJHM. Prevalence of asthma and COPD in general practice in 1992: has it changed since 1977? Br J Gen Pract 1996;46:27781.

8. Littlejohns P, Ebrahim S, Anderson R. Prevalence and diagnosis of chronic respiratory symptoms in adults. $B M J 1989 ; 298$ :155660.

9. Renwick DS, Connolly MJ. Prevalence and treatment of chronic airways obstruction in adults over the age of 45. Thorax 1996; 51:164-8.

10. Thiadens HA, De Bock GH, Dekker FW, Huysman JAN, Van Houwelingen JC, Springer MP, Postma DS. Identifying asthma and chronic obstructive pulmonary disease in-patients with persistent cough presenting to general practitioners: a descriptive study. BMJ 1998; 316:1286-90.

11. Dickinson JA, Meaker M, Searle M, Ratcliffe G. Screening older patients for obstructive airways disease in a semi-rural practice. Thorax 1999;54: 501-05.

12. Crockett, A. Screening older patients for obstructive airways disease. Thorax 1999;472-3.

13. van den Boom G, van Schayck CP, Rutten-van Molken MPMH, Tirimanna PRS, den Otter JJ, van Grunsven PM, Buitendijk MJ, van Herwaarden CLA, van Weel C. Active detection of Chronic Obstructive Pulmonary Disease and Asthma in the General Population: Results and Economic Consequences of the DIMCA Program. Am J Respir Crit Care Med 1998 158:1730-8. 